Dimensiones del latinoamericanismo

Mabel Moraña (ed.) 


\section{South by Midwest}

6

Esta serie, auspiciada por Washington University in St. Louis, presenta publicaciones individuales o colectivas sobre temas de política, cultura y sociedad latinoamericanas, proponiéndose como una plataforma de intercambio y debate para el latinoamericanismo internacional. Se favorecen estudios teóricos, enfoques críticos e historiográficos tendientes a incorporar al estudio de América Latina perspectivas provenientes de los estudios culturales, poscoloniales, etc.

\section{Directora:}

Mabel Moraña (Washington University in St. Louis)

\section{Consejo editorial:}

Juan Ricardo Aparicio (Universidad de los Andes, Bogotá)

Román de la Campa (University of Pennsylvania, Philadelphia)

Debra Ann Castillo (Cornell University, Ithaca)

Sara Castro-Klarén (Johns Hopkins University, Baltimore)

Beatriz González-Stephan (Rice University, Houston)

Susanne Klengel (Freie Universität Berlin)

Anne Lambright (Trinity College, Hartford)

José Ignacio López Soria (Universidad Antonio Ruiz de Montoya, Lima)

José Antonio Mazzotti (Tufts University, Medford)

Carmen de Mora (Universidad de Sevilla)

Ineke Phaf-Rheinberger (RWTH Aachen)

Juan Poblete (University of California, Santa Cruz)

José Manuel Valenzuela Arce (El Colegio de la Frontera Norte, Tijuana) 


\title{
Dimensiones del latinoamericanismo
}

\author{
Mabel Moraña (ed.)
}

Iberoamericana • Vervuert • 2018 
Cualquier forma de reproducción, distribución, comunicación pública o transformación de esta obra solo puede ser realizada con la autorización de sus titulares, salvo excepción prevista por la ley. Diríjase a CEDRO (Centro Espańol de Derechos Reprográficos) si necesita fotocopiar o escanear algún fragmento de esta obra (www.conlicencia.com; 917021970 / 9327204 47).

Reservados todos los derechos

(C) Iberoamericana, 2018

Amor de Dios, $1 \cdot$ E-28014 Madrid

Tel. +34914293522

Fax +34914295397

info@iberoamericanalibros.com

www.iberoamericana-vervuert.es

(C) Vervuert, 2018

Elisabethenstr. 3-9 - D-60594 Frankfurt am Main

Tel. +49695974617· Fax +49695978743

info@iberoamericanalibros.com

www.iberoamericana-vervuert.es

ISBN 978-84-16922-74-1 (Iberoamericana)

ISBN 978-3-95487-696-9 (Vervuert)

ISBN 978-3-95487-697-6 (e-Book)

Depósito Legal: M-5450-2018

Diseño de cubierta: Carlos Zamora

Realización: Negra

Impreso en España. Printed in Spain

The paper on which this book is printed meets the requirements of ISO 9706 